This item was submitted to Loughborough's Research Repository by the author.

Items in Figshare are protected by copyright, with all rights reserved, unless otherwise indicated.

\title{
Removal of the selected pesticides from a water solution applying hollow fiber liquid-liquid membrane extraction
}

PLEASE CITE THE PUBLISHED VERSION

http://dx.doi.org/10.1021/ie404210k

PUBLISHER

(C) American Chemical Society

VERSION

AM (Accepted Manuscript)

LICENCE

CC BY-NC-ND 4.0

\section{REPOSITORY RECORD}

Djordjevic, Jelena S., Goran T. Vladisavljevic, and Tatjana M. Trtic-Petrovic. 2014. "Removal of the Selected Pesticides from a Water Solution Applying Hollow Fiber Liquid-liquid Membrane Extraction”. figshare. https://hdl.handle.net/2134/14432. 
This item was submitted to Loughborough's Institutional Repository (https://dspace.lboro.ac.uk/) by the author and is made available under the following Creative Commons Licence conditions.

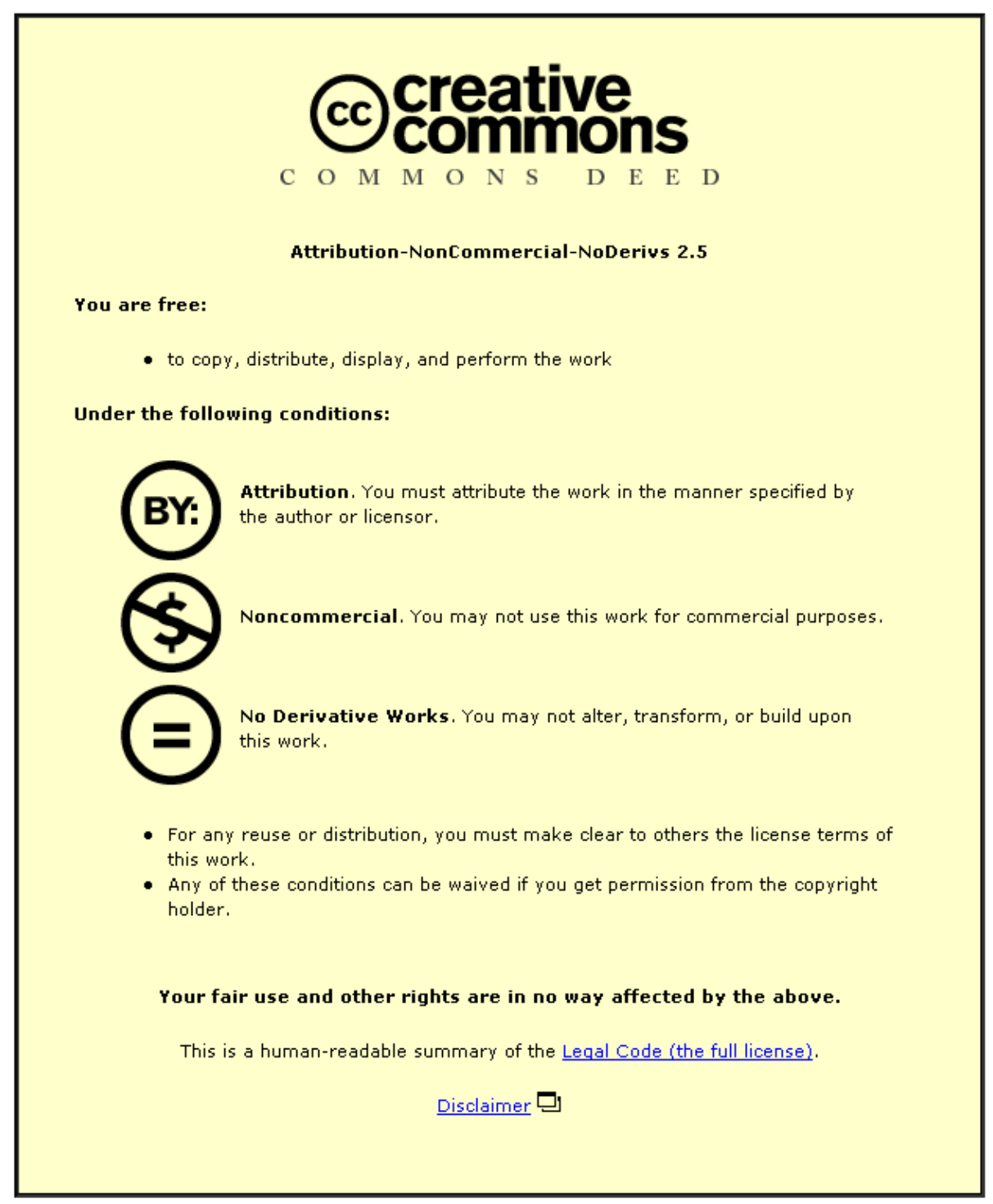

For the full text of this licence, please go to: http://creativecommons.org/licenses/by-nc-nd/2.5/ 


\title{
Removal of the Selected Pesticides from a Water
}

\section{Solution Applying Hollow Fiber Liquid-liquid}

\section{Membrane Extraction}

\author{
Jelena S. Đorđević, Goran T. Vladisavljevićt, ${ }^{\dagger, \S}$, Tatjana M. Trtić-Petrović,** \\ Laboratory of Physics, Vinča Institute of Nuclear Sciences, University of Belgrade, P.O. Box \\ 522, 11001 Belgrade, Serbia \\ ${ }^{\dagger}$ Chemical Engineering Department, Loughborough University, Loughborough, Leicestershire \\ LE11 3TU, UK \\ ${ }^{\S}$ Laboratory of Chemical Dynamics and Permanent Education, Vinča Institute of Nuclear \\ Sciences, University of Belgrade, P.O. Box 522, 11001 Belgrade, Serbia
}

KEYWORDS. hollow fiber contactor, liquid-liquid membrane extraction, mass transfer coefficient, supported liquid membrane, pesticide.

ABSTRACT. A supported liquid membrane extraction of different pesticides (acetamiprid, dimethoate, imidacloprid, linuron, and tebufenozide) from an aqueous solution containing $20 \mathrm{mg}$ $\mathrm{dm}^{-3}$ of each pesticide by $5 \%$ TOPO (tri-n-octylphosphine oxide) in DHE (di-n-hexyl ether) has been investigated in a hollow fiber contactor having an aqueous feed/organic interfacial area of 
$15.4 \mathrm{~cm}^{2}$. In a single-pass operation, the maximum removal efficiency of $95 \%$ was achieved for the most nonpolar $\left(\log P=4.38\right.$ ) pesticide tebufenozide at the feed flow rate of $0.5 \mathrm{~cm}^{3} \mathrm{~min}^{-1}$. The diffusion through the boundary layer of the feed stream was a rate-controlling step in the extraction of nonpolar pesticides (linuron and tebufenozide) with a mass transfer coefficient in the feed stream being proportional to the feed flow rate raised to the power of $0.51-0.57$. The maximum overall mass transfer coefficient based on the feed phase of $K_{F}=0.18 \mathrm{~cm} \mathrm{~min}^{-1}$ was obtained for tebufenozide at the feed flow rate of $1.8 \mathrm{~cm}^{3} \mathrm{~min}^{-1}$. The organic phase entrapped in the membrane pores offered a major resistance to the mass transfer of polar pesticides $(\log P<1)$ and accounted for $85 \%$ of the overall mass-transfer resistance for imidacloprid at $1.8 \mathrm{~cm}^{3} \mathrm{~min}^{-1}$. The pesticides removed from the feed solution were almost completely accumulated in the organic phase, but were recovered from the membrane pores to a large extent (50-90\%) by rinsing the membrane with methanol after extraction.

\section{Introduction}

Pesticide residues can reach the aquatic environment through direct runoff from agricultural land, leaching, careless disposal of empty pesticide containers, and cleaning pesticide application equipment. Industrial wastewaters generated by equipment cleaning contain pesticides and various ingredients that increase pesticidal activity, improve safety features, and enhance handling and storage qualities of pesticide formulations. The concentration of toxic compounds in industrial wastewaters should be reduced to acceptable levels before they can be released to the receiving water streams. For example, the maximum allowable concentration of pesticides in the industrial wastewater discharged into sewage or aquatic environment is $0.05 \mathrm{mg} \mathrm{dm}^{-3} .^{1-3}$

A wide range of physical, physicochemical, biological and chemical methods can be used to remove pollutants from wastewaters including sedimentation, coagulation / flocculation, 
filtration, adsorption, oxidation processes, distillation, ion exchange, solvent extraction processes, dialysis, electodrodialysis, and other membrane separation processes. ${ }^{4}$ Conventional wastewater treatment comprises several stages such as preliminary treatment, primary treatment, secondary treatment and tertiary treatment, which depend on the type and concentration of pollutants. ${ }^{5}$ Among advanced wastewater treatment processes, liquid membrane (LM) separation techniques have clearly emerged as one of the most promising alternatives to conventional processes due to their inherent advantages, such as the ability to perform extraction and reextraction simultaneously as a single technological step, to use gradient of chemical energy as a driving force, and to transfer pollutants from an area of low concentration to an area of high concentration because of the non-equilibrium nature of the process, thereby achieving simultaneous purification and concentration of pollutants. ${ }^{6}$

A variety of different LM configurations have been used in wastewater treatment: bulk LM, surfactant or emulsion LM, supported LM (SLM), electrostatic pseudo LM, supported emulsion LM, hollow fiber contained LM, hollow fiber renewal LM, etc. ${ }^{6--9}$ The advantages of LM over conventional liquid-liquid extraction and solid membrane techniques are in high enrichment factors and fluxes, low consumption of energy, low consumption of extractant (,green chemistry“) due to its continual regeneration by re-extraction, low capital and operation costs, and ease of operation and control.

Non-dispersive liquid-liquid membrane extraction (LLME) has been used for the removal of metal ions, such as $\mathrm{Cu}(\mathrm{II})^{10}$ and $\mathrm{Cr}(\mathrm{VI})^{11}$, and organic pollutants ${ }^{12}$ from wastewater, separation of radionuclides, ${ }^{13,14}$ extraction of pesticides from natural waters, ${ }^{15}$ etc. Two types of LLME have been used: (i) two-phase system, where the aqueous phase is at one side of the membrane and the organic phase partly in the membrane pores and partly at the other side of the membrane, and (ii) 
three phase system (SLM), where the organic phase is in the membrane pores and the two aqueous phases (feed and stripping) are at the opposite side of the membrane. LLME can be performed with flat sheet membrane and hollow fiber membrane. ${ }^{15}$

The advantages of non-dispersive LLME are: (i) since the mixing of phases is avoided, problems of flooding, loading or downstream phase separation cannot occur, so that the feed and solvent flow rates can be adjusted independently and the difference in density between the aqueous and organic phase becomes unimportant leading to a greater choice of solvents; (ii) the specific interfacial area of $500-5000 \mathrm{~m}^{2} \mathrm{~m}^{-3}$ is very high compared to $20-500 \mathrm{~m}^{2} \mathrm{~m}^{-3}$ in conventional contactors; and (iii) the process can be automated. The problems that hindered the wider application of LLME for industrial wastewater treatment are the poor stability of LM leading to the leakage of organic phase from the pores and the existence of membrane resistance. Several modifications have been made to reduce the loss of organic phase, including gelling and polymerization of LM in the pores and the formation of a thin polymeric coating over the membrane pores. ${ }^{16}$

Wastewater treatment technologies for removal of pesticide active ingredients include emulsion breaking by acid addition and temperature control, activated carbon adsorption, chemical oxidation (usually by sodium hypochlorite), chemical precipitation (in the form of sulfides, hydroxides, and carbonates), and hydrolysis. ${ }^{17}$ The removal of pesticides in a wastewater treatment plant depends on the type of pesticide and the separation process applied. Morasch et al. ${ }^{18}$ found that the treatment based on chemical precipitation followed by either sedimentation or an activated sludge process resulted in high removal efficiencies (70-98\%) for chloridazon, tebufenozide, IPBC, and irgarol, the removal of carbendazim, diazionon and terbutryn was poor, whereas some pesticides such as atrazine, mecopropo, and propiconazole 
were not eliminated at all. Singer at al. ${ }^{19}$ found that the removal of several pesticides in a wastewater treatment plant after secondary (activated sludge) and tertiary (sand filtration) treatment were below 50\%. Gupta et al. $^{20}$ removed $91 \%$, 82\% and 72\% of methoxychlore, atrazine and methyl parathion, respectively using activated carbon adsorption. They correlated the degree of adsorption achieved with octanol/water partition coefficient $(\log P)$.

Removal of pesticides from industrial wastewaters was found to vary significantly due their versatile chemical composition (they contain different functional groups and exhibit a wide range of polarity and acidic characteristics), their concentrations are variable and the matrix is complex. In our previous study, we have investigated the effects of physicochemical properties of pesticides and extractant type on two-phase membrane extraction of 16 different pesticides from the river water. ${ }^{15}$ The experiments were performed in a single hollow fiber device and the aim was to determine of very low pesticides concentration in natural water samples. The main propose of this study was to investigate the removal of targeted pesticides from the aqueous solution using supported liquid phase extraction in a self-constructed hollow fiber (HF) contactor. Five pesticides of different polarity were chosen as a model system. The experimental conditions are selected based on our prior experience. ${ }^{15}$ The influence of feed flow rate and physicochemical properties of pesticides on the removal efficiency, the overall mass transfer coefficient and the overall mass-transfer resistance were investigated. The applicability of supported liquid membrane (SLM) extraction for single-stage processing of industrial wastewaters was discussed.

\section{Experimental}

\subsection{Materials}


The following pesticides were studied in this work: acetamiprid (ACT, N-[(6-chloro-3pyridyl)methyl]-N'-cyano- $N$-methyl-acetamidine), dimethoate $\quad$ (DIM, $O, O$-dimethyl $S$-[2(methylamino)-2-oxoethyl]dithiophosphate), ～imidacloprid $\quad$ (IMI, $\quad N$-[1-[(6-chloro-3pyridyl)methyl]-4,5-dihydroimidazol-2-yl]nitramide), linuron (LNR, 3-(3,4-dichlorophenyl)-1methoxy-1-methylureum), and tebufenozide (TEB, $\quad N$-tert-butyl- $N$ '-(4-ethylbenzoyl)-3,5 dimethylbenzohydrazide). All pesticides (purity 95\% w/w) were obtained from GalenikaFitofarmacija A.D. (Zemun, Serbia). Tri-n-octylphosphine oxide (TOPO), di- $n$-hexyl ether (DHE), methanol, $n$-isopropanol, and $\mathrm{HCl}$ were of analytical grade and purchased from SigmaAldrich (St. Louis, MO, USA). Celgrad X-20 microporous hydrophobic polypropylene HF membrane was obtained from Hoechst Celanese Co. (USA).

Stock solutions of pesticides $\left(200 \mathrm{mg} \mathrm{dm}^{-3}\right.$ ) were prepared in methanol and stored at $-20^{\circ} \mathrm{C}$. Aqueous feed solutions containing $20 \mathrm{mg} \mathrm{dm}^{-3}$ of each pesticide were prepared on a daily basis by an appropriate dilution of the stock solution with Milli-Q deionized water (Millipore Corporation, Bedford, MA, USA).

\subsection{Experimental setup and procedures}

A microporous hollow-fiber contactor was constructed according to the design reported previously. $^{21,22}$ The HFs were inserted in an open glass tube and potted by epoxy resin at both ends of the tube. Inlet and outlet ports were connected to the extracapillary space of the contactor to provide flow of the acceptor phase outside the fibers. The main characteristics of the contactor and HF membrane are given in Table 1 . All materials used in the contactor were resistant to $\mathrm{HCl}$, DHE and TOPO.

Table 1. The characteristics of the hollow fibers and membrane contactor used in this work.

\begin{tabular}{|l|l|}
\hline Length of contactor, $\mathrm{cm}$ & 15.0 \\
\hline
\end{tabular}




\begin{tabular}{|l|l|}
\hline Inner diameter of glass shell, $\mathrm{cm}$ & 1.4 \\
\hline Number of fibers in module, $N$ & 50 \\
\hline Effective fiber length, $L, \mathrm{~cm}$ & 12.0 \\
\hline Inner fiber diameter, $d_{i, \mu \mathrm{m}}$ & 280 \\
\hline Outer fiber diameter, $d_{o}, \mu \mathrm{m}$ & 660 \\
\hline Thickness of fiber wall, $\delta, \mu \mathrm{m}$ & 190 \\
\hline Pore diameter, $d_{p}, \mu \mathrm{m}$ & 0.1 \\
\hline $\begin{array}{l}\text { Membrane wall porosity, } \varepsilon, \% \\
\text { Effective outer surface area of the } \\
\text { membrane, } A_{o}, \mathrm{~cm}^{2}\end{array}$ & 28 \\
\hline $\begin{array}{l}\text { Effective inner surface area of the } \\
\text { membrane, } A_{i}, \mathrm{~cm}^{2}\end{array}$ & 15.4 \\
\hline \begin{tabular}{l} 
Volume of organic phase, $V_{o}, \mathrm{~cm}^{3}$ \\
\hline
\end{tabular} & 0.4 \\
\hline
\end{tabular}

The experimental rig shown in Fig. 1 consisted of a hollow fiber contactor (C), three glass reservoirs of $100 \mathrm{~cm}^{3}$ volume for the feed (donor) solution (F), raffinate (R) (the feed solution at the outlet of the contactor) and the acceptor phase (A), two variable speed peristaltic pumps (P1 and P2) (Masterflex C/L, Cole-Parmer Instruments Co., USA), and Masterflex Norprene tubing with an inner diameter (ID) of $0.56 \mathrm{~mm}$ or $0.89 \mathrm{~mm}$ (PharMed, Cole-Parmer Instruments Co., USA). The tubing of $0.56 \mathrm{~mm}$ ID was used only when the flow rate was $0.5 \mathrm{~cm}^{3} \mathrm{~min}^{-1}$, while the $0.89 \mathrm{~mm}$ ID tubing was used for all other flow rates. The similar experimental set-up was used in previous investigations. $^{21--23}$ 


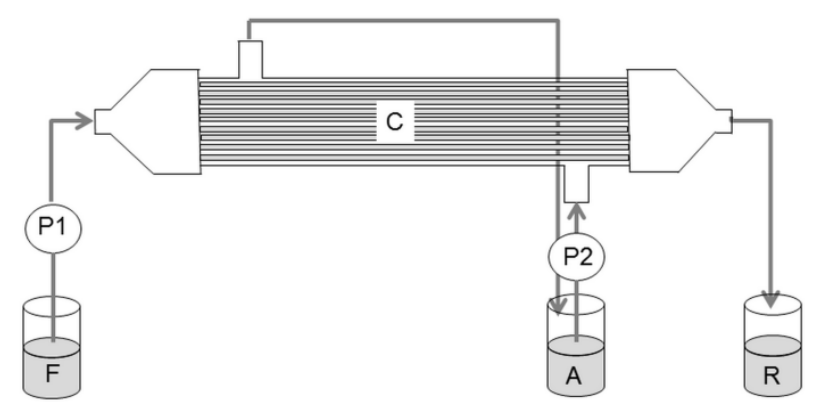

Figure 1. Schematic diagram of the experimental set-up: C - contactor, P1 - P2 - peristaltic pumps, F - feed solution, A - acceptor solution, R- raffinate.

Since the membrane was hydrophobic, the pores were filled with the organic phase (5\% TOPO in DHE), which was done by pumping the organic phase through the lumen of the HF. After filling the membrane pores with the extractant, both sides of the membrane were rinsed with water. The extracapillary space of the contactor was then filled with the acceptor phase (2 mol $\mathrm{dm}^{-3} \mathrm{HCl}$ ), which was kept stagnant during the extraction process. The feed solution was continuously pumped through the lumen of the fibers at a flow rate ranging from 0.5 to $1.8 \mathrm{~cm}^{3}$ $\min ^{-1}$. Samples of $0.5 \mathrm{~cm}^{3}$ were taken at the outlet of the feed phase, in regular time intervals, and used to determine the pesticides concentration. The concentration of pesticides in the acceptor phase was determined at the end of the extraction. All experiments were carried out at constant temperature of $22^{\circ} \mathrm{C}$.

After each experiment, the acceptor was first removed from the shell of the contactor. The lumen side of the fibers was rinsed with $5 \mathrm{~cm}^{3}$ of methanol and then with plenty of water under relatively high flow rate to force water through the pores and finally, the glass shell was rinsed with water.

Chromatographic analysis was performed using Agilent 1100 liquid chromatograph (Agilent Technologies, USA) with Zorbax XDB-C18 column $(4.6 \mathrm{~mm} \times 250 \mathrm{~mm}, 3.5 \mu \mathrm{m}$ particle size, 
Agilent Technologies, USA) and diode-array detector at $254 \mathrm{~nm}$. The flow rate was $0.7 \mathrm{~cm}^{3} \mathrm{~min}^{-}$

${ }^{1}$ and an aliquot of $20 \mu$ l of the sample was injected into HPLC system. The mobile phase consisted of methanol (A) and deionized water (B), using the following gradient profile: 0.0 min 43\% $\mathrm{A}$ and $57 \% \mathrm{~B}$, then $7 \mathrm{~min} 70 \% \mathrm{~A}$ and $30 \% \mathrm{~B}$, and $20 \mathrm{~min}$ returned to the initial composition. The system was controlled by the ChemStation software.

The partition coefficients, $m_{F}$, of the pesticides between the organic phase (5\% TOPO in DHE) and the feed phase were determined by mixing $0.2 \mathrm{~cm}^{3}$ of the extractant and $5 \mathrm{~cm}^{3}$ of the feed solution for $2 \mathrm{~min}$ in the vortex agitator followed by shaking for $1 \mathrm{~h}$ on the laboratory shaker.

The dissociation constants, $\mathrm{p} K_{a}$, and $n$-octanol-water partition coefficients, $\log P$, of the investigated pesticides were calculated using the computer software ACD/Labs PhysChem Suite v12 (Advanced Chemistry Development Inc., Toronto, Canada).

\section{Theoretical background}

\subsection{Efficiency of SLM extraction process}

The efficiency of mass transfer of a pesticide through the liquid membrane was evaluated using several performance parameters including the removal efficiency $\left(E_{R}\right)$, the extraction efficiency $(E)$, the mean flux across the membrane $\left(J_{m}\right)$, the overall mass transfer coefficient $\left(K_{F}\right)$, and the overall mass transfer resistance $(R)$.

The removal efficiency is defined as the amount of pesticide removed from the feed phase with respect to the initial amount of pesticide in the feed phase:

$E_{R}=\frac{\left(C_{F}^{\text {in }}-C_{F}^{\text {out }}\right)}{C_{F}^{\text {in }}}$

where $C_{F}^{\text {in }}$ and $C_{F}^{\text {out }}$ is the pesticide concentration in the feed and raffinate, respectively. 
The extraction efficiency is the ratio between the number of moles of pesticide collected in the acceptor phase $\left(n_{A}\right)$ and the initial number of moles of pesticide in the feed phase $\left(n_{F}^{i n}\right)$ :

$E=\frac{n_{A}}{n_{F}^{i n}}=\frac{C_{A} V_{A}}{C_{F}^{i n} V_{F}}=\frac{C_{A} V_{A}}{C_{F}^{i n} Q_{F} t}$

where $C_{A}$ is the concentration of pesticide in the acceptor phase, $V_{F}$ and $V_{A}$ is the volume of the feed and acceptor phase, respectively, $Q_{F}$ is the feed flow rate, and $t$ is the extraction time. $E_{R}$ depends on the partition coefficient of pesticide between the aqueous feed and organic phase and the feed flow rate in the contactor.

Mass transfer kinetics of pesticide in SLM extraction system can be described using the resistance-in-series approach. According to this approach, the mass transfer of a solute through SLM includes three steps: (i) diffusion from the feed phase to the feed/organic interface, (ii) diffusion through the organic phase entrapped within the membrane pores, and (iii) diffusion from the organic/strip interface to the bulk of the acceptor phase. ${ }^{24}$ If the extraction is accompanied by chemical reactions, e.g. formation and decomposition of a solute-carrier complex at the feed/organic and organic/strip interface, respectively, the reaction rate terms must be included in the mass transfer coefficient. ${ }^{25}$ For diffusion-controlled mass transfer through SLM (i.e. no interfacial complexation reaction or very fast reaction compared to the rate of diffusion), the overall mass-transfer resistance is a sum of series resistances comprised of the feed phase, organic phase, and acceptor phase:

$$
R=\frac{1}{K_{F}}=\frac{1}{k_{F}}+\frac{d_{i}}{k_{M} d_{L M} m_{F}}+\frac{d_{i}}{k_{A} d_{o} m_{A}}
$$

$K_{F}$ is the overall mass-transfer coefficient based on the driving force in the feed phase, $k_{F}, k_{M}$, and $k_{A}$ are the mass transfer coefficient in the feed phase, the organic phase entrapped in the membrane pores, and the acceptor phase, respectively, $d_{i}, d_{o}$, and $d_{L M}$ are the inner, outer, and 
$\log$ mean diameter of a hollow fiber, respectively, $m_{F}$ is the partition coefficient between the organic phase and the feed, and $m_{A}$ is the partition coefficient between the organic phase and the acceptor phase. If the organic phase has a high loading capacity for the solute compared to the amount of solute removed from the feed phase, the overall resistance can be regarded as a sum of the feed resistance and the membrane resistance:

$R=\frac{1}{k_{F}}+\frac{d_{i}}{k_{M} d_{L M} m_{F}}=r_{F}+r_{M}$

$K_{F}$ can be calculated from the inlet and outlet concentration of pesticide in the contactor at steady state: ${ }^{23,26-28}$

$K_{F}=\frac{Q_{F}\left(C_{F}^{\text {in }}-C_{F}^{\text {out }}\right)}{A_{i} \Delta C_{L M}}$

where $A_{i}$ is the effective inner surface area of the membrane $\left(A_{i}=\pi d_{i} L N \varepsilon\right)$ with respect of membrane porosity, $\varepsilon, L$ is the effective fiber length, $N$ is the number of fibers in the contactor, and $\Delta C_{L M}$ is the log mean concentration driving force in the feed phase.

The membrane mass transfer coefficient $k_{M}$ can be predicted from the membrane pore morphology and the diffusivity of a solute in the extractant:

$k_{M}=\frac{D \varepsilon}{\delta \tau}$

where $\delta$ and $\tau$ are the thickness and pore tortuosity of the HF wall, respectively. $D$ can be estimated from Wilke-Chang or Scheibel correlation. ${ }^{29}$

The mean flux $\left(J_{m}\right)$ of pesticide across SLM at steady state is given by:

$J_{m}=\frac{Q_{F}}{A_{i}}\left(C_{F}^{\text {in }}-C_{F}^{\text {out }}\right)=K_{F} \Delta C_{L M}$

The effective fiber length $(L)$ can be expressed as a product of the length of a transfer unit $(L T U)$ and the number of transfer units $(N T U)$ : 
$L=\frac{4 Q_{F}}{K_{F} \pi d_{i} N} \ln \left(\frac{C_{F}^{\text {in }}}{C_{F}^{\text {out }}}\right)=L T U \times N T U$

\section{Results and discussion}

\subsection{Selection of pesticides}

The main characteristics of the investigated pesticides (ACT, DIM, IMI, LNR, and TEB) are listed in Table 2. The pesticides have been selected in such a way that they exhibit different activity and polarity and belong to different chemical classes. As can be seen from Table 2, the targeted pesticides are either very week acids (pKa 0.7 for ACT) or very week bases (pKa higher than 10.9). Its means that the selected pesticides are in uncharched form over a wide $\mathrm{pH}$ range (2-9) covering natural and waste water. The $\log P$ values of the targeted pesticides are in the range between 0.46 and 4.38, and constant in the $\mathrm{pH}$ range from 2.0 to $10.0{ }^{15,30}$ Based on these values it can be concluded that more hydrophobic pesticides with $\log P>2$ can easily be extracted using non-polar organic solvents. In this work DHE was chosen as a solvent due to its favorable characteristics in membrane extraction, such as long-term stability of SLM. ${ }^{31}$ In order to achieve an efficient extraction of less hydrophobic pesticides $(\log P<2)$, the polarity of liquid membrane must be increased by adding polar extractants such as TOPO or tri- $n$-butylphosphate. A high polarity of TOPO is a result of the phosphorus-oxygen bond that can interact with polar groups of pesticides through hydrogen bonding. TOPO is miscible in nonpolar solvents such as DHE because of the presence of three octyl groups in the molecule. In this work 5\% TOPO in DHE was used as a liquid membrane to achieve simultaneous extraction of polar and nonpolar pesticides. ${ }^{15}$ Based on $\log P$ of the studied pesticides, it can be concluded that these compounds cannot easily be reextracted into the acceptor phase. However, three-phase system was selected because of very low hold-up volume of the organic phase in the module and based on the assumption that the loading capacity of the organic phase was sufficiently high. Due to small 
amount of organic phase in the module, a three-phase extraction process is safer, cheaper and more environmentally friendly than the two-phase process.

Table 2. The main characteristics of targeted pesticides.

\begin{tabular}{|c|c|c|c|c|}
\hline $\begin{array}{l}\text { Pesticide } \\
\text { (Abbr.) }\end{array}$ & $\begin{array}{l}\text { Chemical class } \\
\text { (activity) }\end{array}$ & Structure & $\mathrm{p} K_{a}$ & $\begin{array}{l}\log P \\
\text { at } \mathrm{pH}=2-10\end{array}$ \\
\hline $\begin{array}{l}\text { Imidacloprid } \\
\text { (IMI) }\end{array}$ & $\begin{array}{l}\text { Neonicotinoid } \\
\text { (insecticide) }\end{array}$ & & $11.2^{\mathrm{a}}$ & $\begin{array}{l}0.46^{\mathrm{b}} \\
0.57^{\mathrm{a}}\end{array}$ \\
\hline $\begin{array}{l}\text { Acetamiprid } \\
\text { (ACT) }\end{array}$ & $\begin{array}{l}\text { Neonicotinoid } \\
\text { (insecticide) }\end{array}$ & & $0.7^{\mathrm{a}}$ & $0.8^{\mathrm{a}}$ \\
\hline $\begin{array}{l}\text { Dimethoate } \\
\text { (DIM) }\end{array}$ & $\begin{array}{l}\text { Organophoshate } \\
\text { (insecticide) }\end{array}$ & & $14.4^{\mathrm{b}}$ & $1.37^{\mathrm{b}}$ \\
\hline $\begin{array}{l}\text { Linuron } \\
\text { (LNR) }\end{array}$ & $\begin{array}{l}\text { Phenylurea } \\
\text { (herbicide) }\end{array}$ & & $12.3^{b}$ & $3.12^{b}$ \\
\hline $\begin{array}{l}\text { Tebufenozide } \\
\text { (TEB) }\end{array}$ & $\begin{array}{l}\text { Diacylhydrazine } \\
\text { (insecticide) }\end{array}$ & & $10.9^{b}$ & $4.38^{b}$ \\
\hline
\end{tabular}

${ }^{\mathrm{a}}$ Ref. 30

bdetermined by the computer software ACD/Labs PhysChem Suite v12

\subsection{Adsorption of pesticides on Norprene tubing}

The adsorption of pesticides on the inner surface of Norprene ${ }^{\circledR}$ tubing was investigated by pumping the feed solution containing $20 \mathrm{mg} \mathrm{dm}^{-3}$ of each pesticide through the tubing and 
measuring their outlet concentrations over $180 \mathrm{~min}$. The flow rate was 0.5 and $1.1 \mathrm{~cm}^{3} \mathrm{~min}^{-1}$ for the tubing with 0.56 and 0.89 mm ID, respectively. The adsorption of LNR, IMI, ACT, and DIM on the inner surface of the Norprene tubes was not observed, as evidenced by the fact that the difference in the pesticide concentration in the aqueous phase before and after passing the tube was within the experimental error $(\leq 5 \%)$. The amount of TEB adsorbed on the $0.56 \mathrm{~mm}$ ID tubing was found to be $24 \pm 2 \%$ at $t=5 \mathrm{~min}$ and $9 \%$ at $t=20 \mathrm{~min}$ pointing out to gradual saturation of the surface with TEB. The adsorption of TEB was not observed at $t>20$ min, probably because the wall of the tubing was fully saturated with TEB. The adsorption of TEB on the $0.89 \mathrm{~mm}$ ID tubing was $12 \%$ at $t=5 \mathrm{~min}$ and less than $5 \%$ at $t=20 \mathrm{~min}$. The TEB adsorption was more pronounced for the narrower bore tubing, due to the higher mass transfer coefficient, $k_{F}$, of TEB from the bulk of the feed phase to the wall surface. According to GraetzLévêque correlation for laminar flow through cylindrical tube: $k_{F} \propto Q_{F}^{0.33} d_{t}^{-1.33}$, where $d_{t}$ is the inner diameter of the tubing. Thus, $k_{F}$ was $42 \%$ higher for $d_{t}=0.56 \mathrm{~mm}$, resulting in the higher adsorption of TEB. After pumping the feed solution, the tubing was rinsed with $20 \mathrm{~cm}^{3}$ of water using the same flow rate as used for the feed solution. It was found that only $6 \%$ of TEB that was adsorbed on the tube was removed by rinsing, indicating that $94 \%$ of TEB was irreversibly adsorbed and the adsorption was completed after $20 \mathrm{~min}$. All experiments in this study were carried out using the Norprene tubing presaturated with TEB, so that the TEB adsorption on the tubing did not occur.

\subsection{The influence of feed flow rate on pesticide concentration in raffinate}

The feed solution was allowed to pass through the fibers in once-through mode and the raffinate was collected at the exit of the contactor (Fig. 1). The acceptor phase was stagnant at the shell side of the contactor (in the extracapillary space). The variations of pesticides 
concentrations in the raffinate (expressed relative to the feed concentration) with time for different feed flow rates are shown in Fig. 2.

The concentration of pesticides in the raffinate at $t=0$ was zero, meaning that the pesticides were completely removed from the feed stream. At the beginning $(t=0)$, the pesticides were dissolving in the organic phase at the feed/organic phase interface with no diffusion through the membrane. Since the interfacial area was limiting, the concentration of pesticides in the organic phase near the feed/organic interface increased causing a decrease in the mass transfer rate to the membrane interface and corresponding increase in $C_{F}^{\text {out }}$ over time i.e. the ratio of $C_{F}^{\text {out }}$ to $C_{F}^{\text {in }}$ of the targeted pesticides increased. In quasi steady-state, the rate of mass transfer to the feed/organic interface was in equilibrium with the rate of diffusion away from the interface to the interior of the organic phase and $C_{F}^{\text {out }}$ was constant. The time required to establish steady state for TEB (Fig. 2(a)) was about 20 min and independent on the flow rate of the feed phase. The time to reach the steady state for LNR (Fig. 2 (b)), ACT (Fig. 2(c)), IMI (Fig 2(d)) and DIM (not shown here) was between 20 and 100 min and was shorter at the lower feed flow rates. 

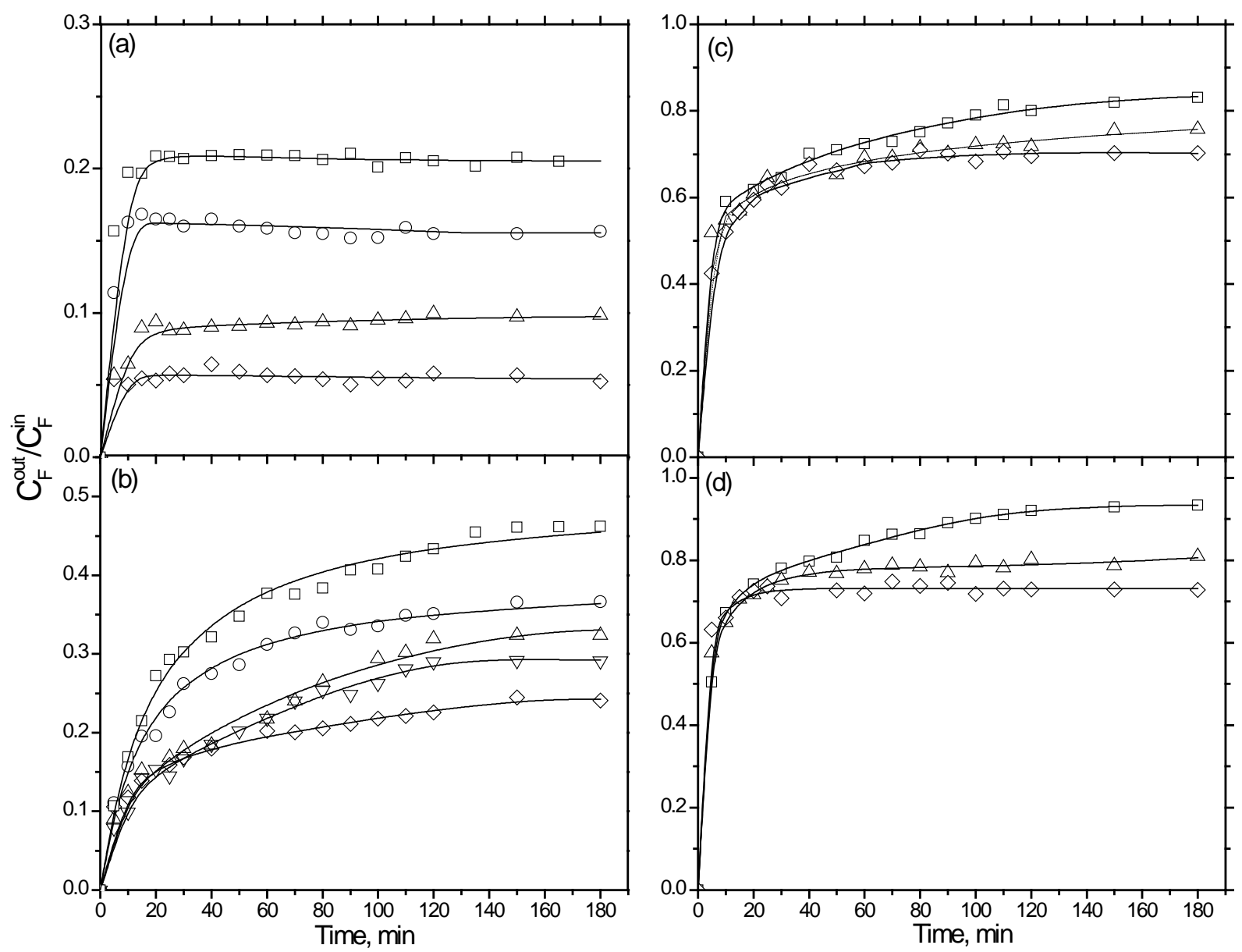

Figure 2. The ratio of the raffinate to the feed concentration for TEB (a), LNR (b), ACT (c), and IMI (d) as a function of time at different feed flow rates. The feed phase was passed through the fibers and the acceptor phase was stagnant at the shell side. Legend: Feed flow rate $\left(\mathrm{cm}^{3} \mathrm{~min}^{-1}\right)$ : $\diamond-0.5, \nabla-0.8, \triangle-1.1, \bigcirc-1.2$, and $\square-1.8$.

The concentration of pesticides in the raffinate, was found to vary significantly with the applied feed flow rate and the $\log P$ value of the pesticides. $C_{F}^{\text {out }}$ increased with increasing the feed flow rate for all pesticides (Fig. 2). The residence time of the feed stream in the contactor for ideal plug flow through the fibers is given by: $t_{R}=\pi d_{i}^{2} L N /\left(4 Q_{F}\right)$. The higher the feed flow 
rate, $Q_{F}$, the shorter the residence time, $t_{R}$, and the smaller the amount of pesticide that can be removed from the feed stream. The minimum amount of pesticide in the raffinate (1 to $4.2 \mathrm{mg}$ $\mathrm{dm}^{-3}$ ) was found for the most hydrophobic pesticide, TEB ( $\log P=4.38$ ), followed by the second most hydrophobic pesticide, LNR ( $\log P=3.12)$, whose concentration in the raffinate was 4.2 to $9.1 \mathrm{mg} \mathrm{dm}^{-3}$. From Fig. 2 (c and d), it can be seen that the polar pesticides with $\log P<1$ (ACT and IMI) were present in the raffinate at much higher levels ( $C_{F}^{\text {out }}>14 \mathrm{mg} \mathrm{dm}^{-3}$ after $\left.180 \mathrm{~min}\right)$ and the influence of feed flow rate on their extraction was much less pronounced than for the pesticides with $\log P>1$.

\subsection{Removal and extraction efficiency}

The removal efficiency, $E_{R}$, of the pesticides from the feed solution at quasi steady state was calculated using Eq. (1) based on $C_{F}^{\text {out }}$ values measured at different feed flow rates (Fig. 3). The removal efficiency decreased linearly with increasing the flow rate of the feed (the $R^{2}$ values ranged from 0.96 to 1.0 ), which was a type of behavior typical for a feed-controlled membranebased solvent extraction. ${ }^{24,32}$ The slopes of the $E_{R}(\%)$ vs. $Q_{F}$ lines in Fig. 3 were -11.4, -16.1, -

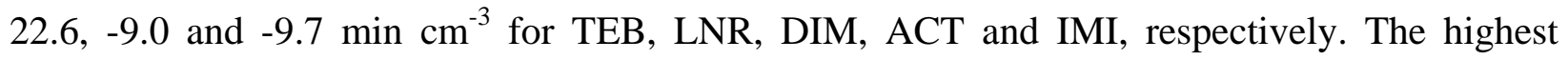
removal efficiency $\left(95 \%\right.$ at $0.5 \mathrm{~cm}^{3} \mathrm{~min}^{-1}$ ) was obtained for TEB, the most nonpolar pesticide used in this work. The effect of the feed flow rate on $E_{R}$ was more pronounced for nonpolar than for polar pesticides. 


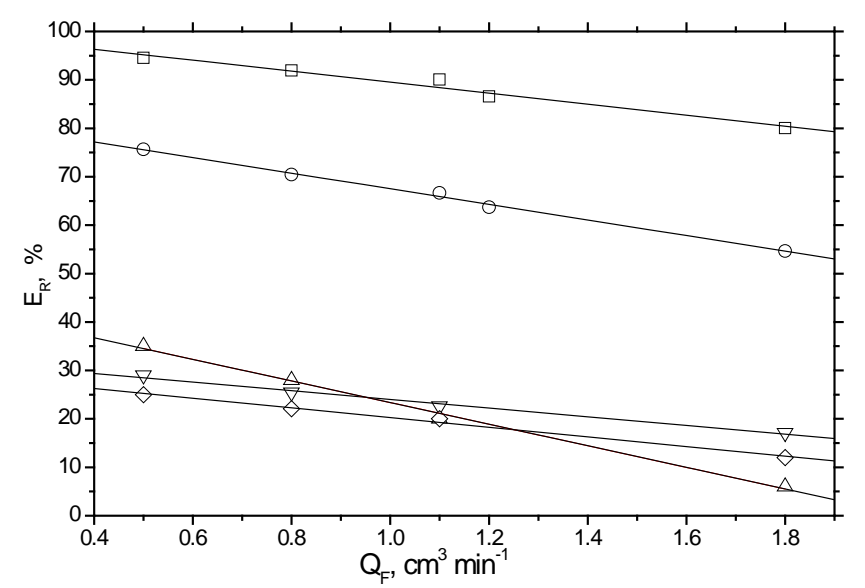

Figure 3. The removal efficiency of the pesticides at quasi steady state as a function of the feed flow rate. The acceptor phase was stagnant at the shell side of the contactor. Legend: $\square$ - TEB, $\bigcirc$ - LNR, $\triangle$ - DIM, $\nabla$ - ACT, $\diamond$ - IMI.

The extraction efficiency, $E$, was found by measuring the pesticide concentration in the acceptor phase at the end of the extraction process (2.82, 2.01, 0.941, 0.978 and $0.786 \mathrm{ppm}$ for TEB, LNR, DIM, ACT and IMI, respectively) and using Eq. (2). The obtained $E$ values were $\leq$ 3\% for TEB and LNR, and $<1 \%$ for DIM, ACT and IMI. It means that the pesticides removed from the feed solution were almost completely accumulated in the organic phase. The accumulation of LNR and TEB in the organic phase derived from their high partition coefficients, resulting in a high loading capacity of the organic phase. E.g., the mass of TEB extracted after $180 \mathrm{~min}$ at $Q_{F}=1.8 \mathrm{~cm}^{3} \mathrm{~min}^{-1}$ was $5.2 \mathrm{mg}$, assuming that $C_{F}^{\text {out }}$ was $4 \mathrm{mg} \mathrm{dm}^{-3}$ and constant over time (Fig. 2(a)). The mean concentration of TEB in the feed stream was about $0.012 \mathrm{mg} \mathrm{cm}^{-3}$, corresponding to the equilibrium concentration of TEB in the organic phase of $170 \mathrm{mg} \mathrm{cm}^{-3}$. The volume of the organic phase in the contactor was $0.52 \mathrm{~cm}^{3}$ (Table 3) and hence the maximum amount of TEB that can be accommodated in the organic phase in the given case was $87 \mathrm{mg}$, which was more than 10 times higher than the amount of TEB removed from the 
feed stream in $3 \mathrm{~h}$. The amount of polar pesticides removed from the feed stream was much smaller (less than $0.6 \mathrm{mg}$ of IMID was extracted after $3 \mathrm{~h}$ at $0.5 \mathrm{~cm}^{3} \mathrm{~min}^{-1}$ ), but the loading capacity of the organic phase was also smaller. Due to insignificant amount of pesticides stripped from the organic phase, the stripping stage was disregarded in the analysis of the overall mass transfer coefficient.

\subsection{Mass transfer coefficient and flux of pesticides}

Fig. 4 shows the overall mass transfer coefficient based on the driving force in the feed phase, $K_{F}$, vs. the feed flow rate, $Q_{F}$, on a log-log scale. $K_{F}$ was calculated from Eq. (5) using steadystate $C_{F}^{\text {out }}$ values from Figure 2. A least-square regression of the data in Fig. 4 gave the following correlations:

$\begin{array}{ll}\text { TEB: } & K_{\text {TEB }}=0.87 \times Q_{F}^{0.510} \\ \text { LNR: } & K_{L N R}=1.15 \times Q_{F}^{0.573} \\ \text { DIM: } & K_{D I M}=1.72 \times Q_{F}^{0.612} \\ \text { ACT: } & K_{A C T}=1.80 \times Q_{F}^{0.544} \\ \text { IMI: } & K_{\text {IMID }}=1.87 \times Q_{F}^{0.409}\end{array}$

Thus, $K_{F} \propto Q_{F}^{b}$ which indicates that $K_{F} \rightarrow 0$ when $Q_{F} \rightarrow 0$, i.e. the overall mass transfer resistance is controlled by the feed phase resistance, $1 / K_{F} \approx 1 / k_{F}$, so that $K_{F} \approx k_{F}$. The correlation coefficients for LNR and TEB $(\geq 0.996)$ are higher than those for polar pesticides (0.984, 0.950 and 0.981 for IMI, ACT, and DIM, respectively), indicating that the high solubility of LNR and TEB in the organic phase favors the feed-phase control of the mass transfer coefficient. The linear relationship between $K_{F}$ and $Q_{F}$ in log-log scale for solvent extraction systems with high distribution coefficients was reported elsewhere. ${ }^{21,33}$ The exponent on $Q_{F}$ in 
Eqs. (9)-(13) ranges from 0.41 for IMI to 0.61 for DIM, which is greater than 0.33 predicted by the Graetz-Lévêque equation for fully developed laminar flow, but below 0.8 predicted by the Chilton-Colburn correlation for turbulent flow.

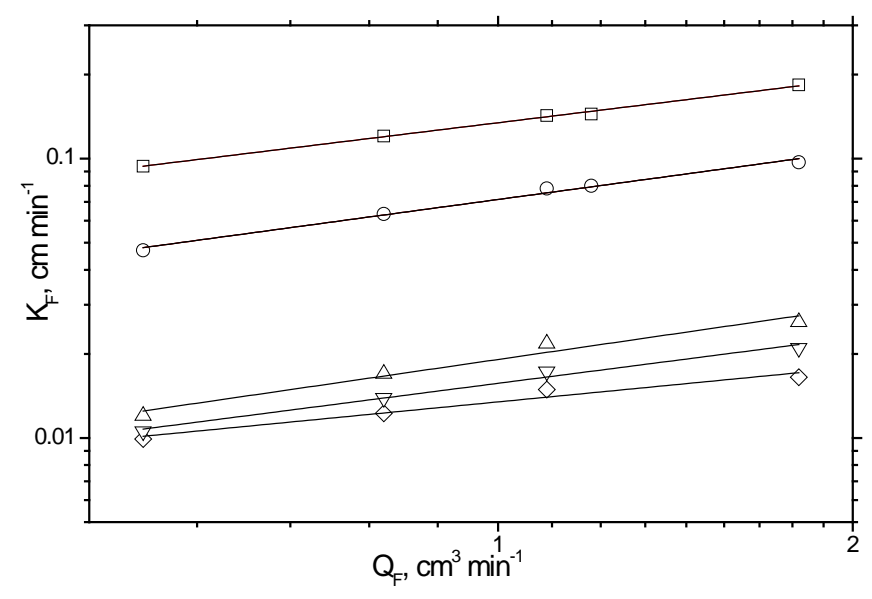

Figure 4. The overall mass transfer coefficient of the pesticides as a function of the feed flow rate. The acceptor phase was stagnant in the shell. Legend: $\square$ - TEB, $\bigcirc$ - LNR, $\triangle$ - DIM, $\nabla$ ACT, $\diamond$ - IMI.

The mechanism of extraction of the investigated pesticides is a partitioning effect and the stripping at the membrane/acceptor interface can be neglected, as confirmed by low $E$ values. Therefore, the mass transfer of the pesticides through SLM takes place in two steps: diffusion of the pesticides through the boundary layer of the aqueous feed phase to the feed/organic membrane interface and diffusion of pesticides through the organic phase entrapped within the membrane pores. Under these conditions, three-phase HF-LLME system can be simplified and treated as a two phase extraction system.

The membrane mass-transfer resistance can be determined graphically from the Wilson plot. This method assumes that the overall mass-transfer resistance is controlled by the flow rate of the mass-transfer-limiting phase, which, in this case, is the feed phase. The Wilson plot of $1 / K_{F}$ 
vs $1 / Q_{F}^{b}$ is shown in Fig. 5 . The values of $b$ used for calculation of $1 / Q_{F}^{b}$ were taken from Eqs. (9)-(13). The intercept on the $1 / K_{F}$ axis represents the mass transfer resistance in the organic phase, $r_{M}^{\text {exp }}$ (the second term in Eq. (3)). As shown in Figure 5 and Table 3, the intercept on the $1 / K_{F}$ axis was virtually zero $\left(\leq 0.7 \mathrm{~cm}^{-1} \mathrm{~min}\right)$ for the pesticides with $\log P>3$ (LNR and TEB), indicating that the resistance offered to the mass transfer by the liquid membrane was negligible compared to the resistance in the feed stream. The intercepts on the $1 / K_{F}$ axis are $10.0,16.8$ and 21.2 for DIM, ACT, and IMI, respectively, and indicate existence of significant mass transfer resistance in the organic phase..

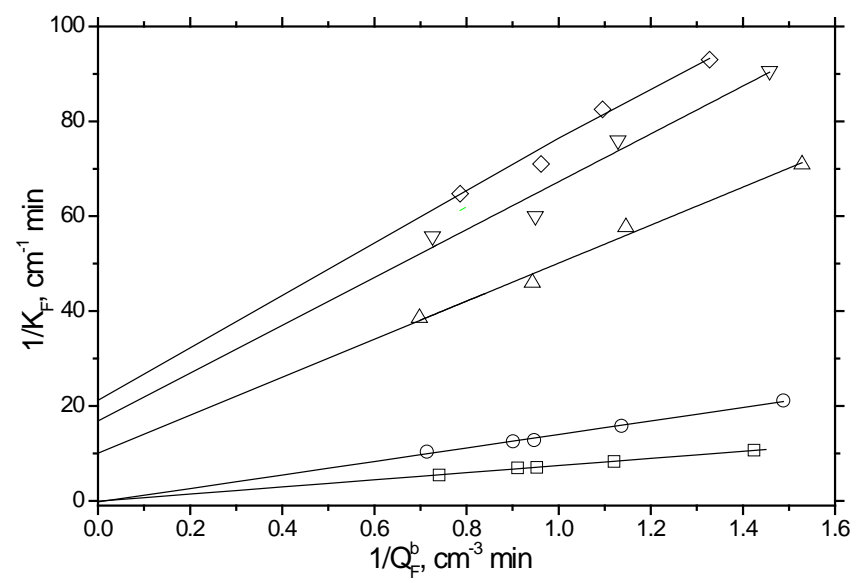

Figure 5. Wilson plot of $1 / K_{F}$ vs $1 / Q_{F}^{b}$. Legend: $\square$ - TEB, $\bigcirc-$ LNR, $\triangle$ - DIM, $\nabla$ - ACT, $\diamond-$ IMI.

The membrane mass-transfer coefficient for the targeted pesticides, $k_{M}$, was calculated using Eq. (6) and the Scheibel equation for $D,{ }^{28}$ based on $\varepsilon=0.28, \delta=190 \mu \mathrm{m}$, and $\tau=2.5^{20}$ (Table 3). The mass transfer resistances in the organic phase $\left(r_{M}^{\text {calc }}\right)$ listed in Table 3 were calculated from the fiber diameters, the partition coefficient $m_{F}$ and $k_{M}$ values using Eq. (3). The $r_{M}^{\text {calc }}$ and $r_{M}^{\text {exp }}$ values are of the same order of magnitude and the difference between the experimental values obtained from the Wilson plot and the calculated values was negligible for more hydrophobic 
pesticides (TEB and LNR), but more significant for more polar pesticides, due to the limited number of experimental data available and/or uncertainties in the calculated values of D for IMI, ACT, and DIM. From Table 3 and Figure 5 it can be seen that the mass transfer resistance of the feed phase was the overwhelming resistance in the extraction of TEB and LNR and its contribution to the overall mass-transfer resistance (calculated based on $r_{M}^{\exp }$ ) was $98.3-99.1 \%$ for TEB and $95-97.5 \%$ for LNR at feed flow rate from $0.5-1.8 \mathrm{~cm}^{3} \mathrm{~min}^{-1}$, respectively. In the case of polar pesticides, the impact of membrane resistance on the overall resistance was significant. E.g., for IMI a contribution of the membrane resistance to the overall mass transfer resistance was $52 \%$ at $0.5 \mathrm{~cm}^{3} \mathrm{~min}^{-1}$ and $85 \%$ at $1.8 \mathrm{~cm}^{3} \mathrm{~min}^{-1}$.

Table 3. The overall resistance $(R)$ to the mass transfer of pesticides at $Q_{F}=0.5-1.8 \mathrm{~cm}^{3} \mathrm{~min}^{-1}$, the experimentally determined mass transfer resistance in the organic phase entrapped in the membrane pores $\left(r_{M}^{\text {exp }}\right)$, the diffusivity $(D)$ of the pesticides in the organic phase calculated using Scheibel equation, the mass transfer coefficient in the organic phase entrapped in the membrane pores $\left(k_{M}\right)$, the partition coefficient $\left(m_{F}\right)$, and the calculated mass transfer resistance in the organic phase entrapped in the membrane pores $\left(r_{M}^{\text {calc }}\right)$.

\begin{tabular}{|l|l|l|l|l|l|l|}
\hline Pesticide & $R$ & $\begin{array}{l}r_{M}^{\text {exp }} \\
\mathrm{cm}^{-1} \min \end{array}$ & $\begin{array}{l}D \\
\mathrm{~cm}^{2} \mathrm{~s}^{-1}\end{array}$ & $\begin{array}{l}k_{M} \\
\mathrm{~cm} \mathrm{~min}^{-1}\end{array}$ & $\begin{array}{l}m_{F} \\
\mathrm{~m}_{M} \\
\mathrm{~cm}^{-1} \mathrm{~min}\end{array}$ \\
\hline ACT & $101-62$ & 21.2 & $3.88 \times 10^{-6}$ & 0.00228 & 12 & 53.0 \\
\hline DIM & $90.9-47.6$ & 16.8 & $3.88 \times 10^{-6}$ & 0.00228 & 19.9 & 31.9 \\
\hline LNR & $21.3-10.4$ & 0.52 & $4.13 \times 10^{-6}$ & 0.0146 & 1320 & 0.71 \\
\hline TEB & $10.6-5.46$ & 0.09 & $3.53 \times 10^{-6}$ & 0.0123 & 13988 & 0.084 \\
\hline
\end{tabular}


It can be concluded that for low polar pesticides (LNR and TEB), the overall mass transfer in the HF-LLME system was controlled by the diffusion in the feed. The mass transfer of these compounds across the boundary layer of the feed phase strongly depends on the feed flow rate and, consequently, the applied system delivered better performances when the feed flow rate was higher. On the other hand, the mass transfer of DMT, ACT, and IMI was predominantly affected by the low partition coefficients $m_{F}$ and the impact of the feed flow rate on the flux through the membrane was limiting, as shown in Fig. 6.

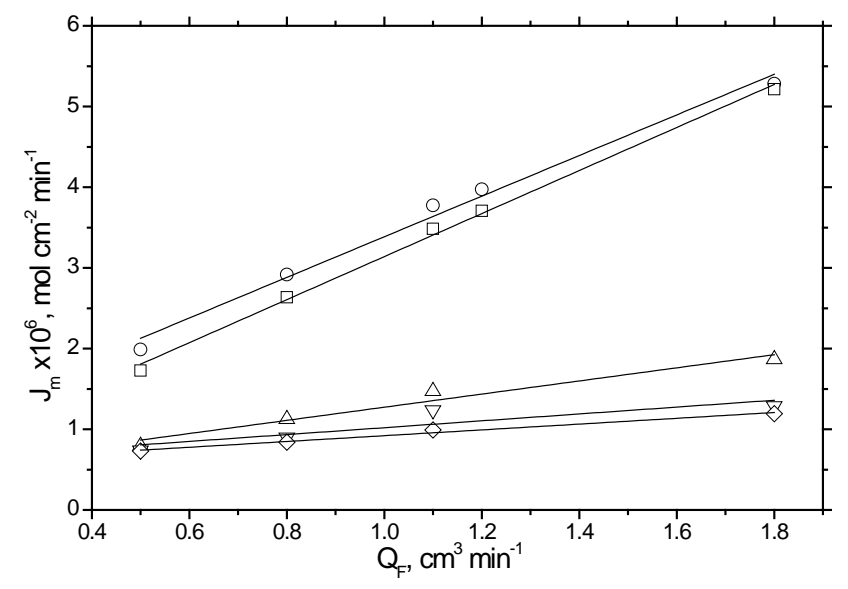

Figure 6. The effect of the feed flow rate on the mean flux of the pesticides across the liquid membrane. The acceptor phase was stagnant. Legend: $\square$ - TEB, $\bigcirc$ - LNR, $\triangle$ - DIM, $\nabla$ - ACT, $\diamond$ - IMI.

Fig. 6 shows the effect of the feed flow rate on the mean flux $\left(J_{m}\right)$ of the pesticides across the membrane. The mean flux was calculated using Eq. (7). A linear relation between the mean flux and the feed flow rate was obtained for all investigated pesticides. The mean flux increased by increasing the aqueous phase flow rate, which was due to an increase in both $K_{F}$ and $\Delta C_{L M}$. The gradient of the $J_{m}$ vs. $Q_{F}$ lines was higher for non-polar pesticides, due to negligible membrane resistance. 


\subsection{Effectiveness of pesticide removal measured in terms of LTU}

Fig. 7 shows the effect of feed flow rate on the length of transfer units ( $L T U)$ calculated using Eq. (8). High values of $L T U$ show poorly contacted phases (short contact time) or inefficient separation. ${ }^{34,35}$ The more efficient the removal of pesticides from the feed phase, the smaller the value of $L T U$. As the feed phase flow rate decreased, $L T U$ decreased (Fig. 7), reflecting the fact that a shorter contactor was needed to achieve a given removal efficiency. The same type of relationship between $L T U$ and $Q_{F}$ was reported by Prasad and Sirkar ${ }^{34}$ and Keurentjes et al. ${ }^{36}$ Fig. 7 shows that LTUs as low as 1.2 and $2.5 \mathrm{~cm}$ were achieved for TEB and LNR at the lowest applied flow rate, respectively, which makes HF-LLME a viable alternative to traditional processes for the removal of nonpolar pesticides from wastewater streams. The similar values (3$15 \mathrm{~cm}$ ) of $L T U$ were reported by Prasad and Sirkar for the extraction of 4-methylthiazole and 4cyanothiazole using a commercial $15 \mathrm{~cm}$ long Liqui-Cel ${ }^{\mathrm{TM}}$ module. ${ }^{37}$ LTUs of polar pesticides were much higher than those for TEB and LNR, but the removal efficiency can be improved by connecting two or more HF contactors in series or using a more suitable extractant with higher partition coefficients of polar pesticides.

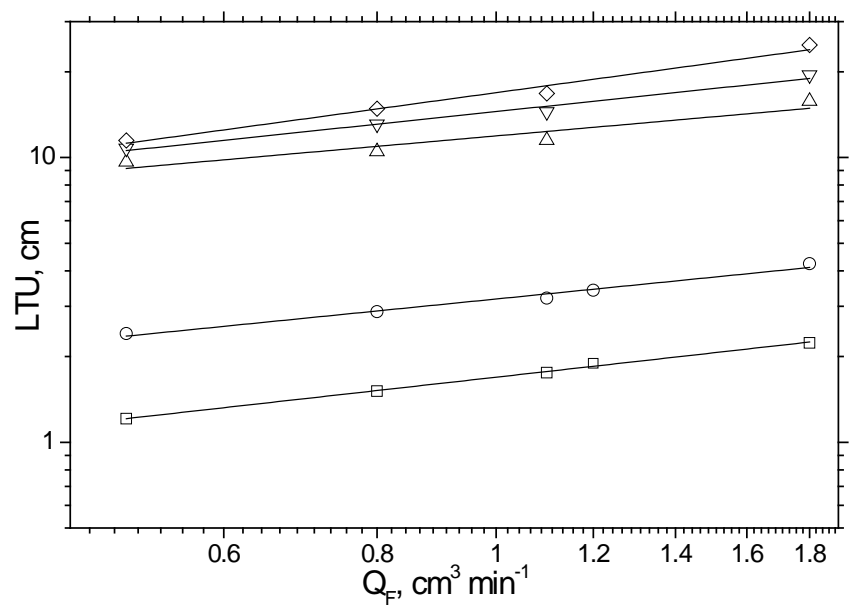


Figure 7. The effect of the feed flow rate on the length of transfer unit ( $L T U)$ in the contactor. Legend: $\square$ - TEB, $\bigcirc$ - LNR, $\triangle$ - DIM, $\nabla$ - ACT, $\diamond$ - IMI.

After the extraction was finished, the membrane was rinsed with methanol using the volume of methanol that was 10 times higher than the volume of the membrane pores. The amount of pesticides in the effluent was measured after rinsing and it was found that $90 \%$ of nonpolar and $50 \%$ of polar pesticides were recovered.

\section{Conclusion}

The applicability of hollow fiber supported liquid membrane extraction has been investigated for the removal of selected pesticides from a dilute aqueous solution. The targeted pesticides (acetamiprid, dimethoate, imidacloprid, linuron, and tebufenozide) were of different activity and polarity ( $\log P=0.46-4.38)$, and belonged to different chemical classes. The maximum overall mass transfer coefficient of $K_{F}=0.18 \mathrm{~cm} \mathrm{~min}^{-1}$ was obtained for tebufenozide at the feed flow rate of $1.8 \mathrm{~cm}^{3} \mathrm{~min}^{-1}$. The diffusion through the boundary layer of the feed stream was a ratecontrolling step in the extraction of nonpolar pesticides (linuron and tebufenozide) with a negligible effect of the organic phase. The organic phase entrapped in the membrane pores contributed significantly to the overall mass transfer rate of polar pesticides $(\log P<1.4)$, due to low aqueous/organic partition coefficients. The maximum single-pass removal efficiency of 95\% was achieved for tebufenozide at the feed flow rate of $0.5 \mathrm{~cm}^{3} \mathrm{~min}^{-1}$. The great majority of each pesticide removed from the feed stream after $3 \mathrm{~h}$ was retained in the organic phase entrapped in the membrane pores, but was recovered to a large extent (50 - $90 \%$ ) by rinsing the membrane with methanol.

\section{AUTHOR INFORMATION}

\section{Corresponding Author}


*Tatjana M. Trtić-Petrović, Laboratory of Physics, Vinča Institute of Nuclear Sciences, University of Belgrade, P.O. Box 522, 11001 Belgrade, Serbia, Email address: ttrtic@vinca.rs, Tel.: +381 11244 7700, Fax: +381112447963

\section{Notes}

The authors have declared no conflict of interest.

\section{ACKNOWLEDGMENT}

We acknowledge the support to this work provided by the Ministry of Education, Science and Technological Development of Serbia through project Physics and Chemistry with Ion Beams, No. III 45006.

\section{ABBREVIATIONS}

ACT, acetamiprid; DHE, di-n-hexyl ether; DIM, dimethoate; HF, hollow fiber; IMI, imidacloprid; LNR, linuron; LLME, liquid-liquid membrane extraction; LM, liquid membrane;

SLM, supported liquid membrane; TEB, tebufenozide; TOPO, tri-n-octylphosphine oxide.

\section{LIST OF SYMBOLS}

$A_{i}=$ effective inner surface area of membrane $\left(\mathrm{cm}^{2}\right)$

$\mathrm{b}=$ gradient of the line in Figure 4

$\mathrm{C}_{\mathrm{A}}=$ concentration of pesticide in the acceptor phase $\left(\mathrm{mg} \mathrm{dm}^{-3}\right)$

$C_{F}^{\text {in }}=$ inlet concentration of pesticide in feed stream $\left(\mathrm{mg} \mathrm{dm}^{-3}\right)$

$C_{F}^{\text {out }}=$ outlet concentration of pesticide in feed stream $\left(\mathrm{mg} \mathrm{dm}^{-3}\right)$

$\Delta C_{L M} \log$ mean concentration driving force in feed stream ( $\mathrm{mg} \mathrm{dm}^{-3}$ ) 
$D=$ diffusivity of pesticide in organic phase $\left(\mathrm{cm}^{2} \mathrm{~s}^{-1}\right)$

$d_{i}=$ inner diameter of a hollow fiber $(\mathrm{cm})$

$d_{o}=$ outer diameter of a hollow fiber $(\mathrm{cm})$

$d_{L M}=\log$ mean diameter of a hollow fiber $(\mathrm{cm})$

$d_{t}=$ inner diameter of tubing $(\mathrm{cm})$

$E=$ extraction efficiency

$E_{R}=$ removal efficiency

$J_{m}=$ mean flux of pesticide $\left(\mathrm{mol} \mathrm{cm}{ }^{-2} \mathrm{~min}^{-1}\right)$

$k_{A}=$ mass transfer coefficient for the acceptor phase $\left(\mathrm{cm} \mathrm{min}^{-1}\right)$

$K_{F}=$ overall mass-transfer coefficient based on the feed phase $\left(\mathrm{cm} \mathrm{min}^{-1}\right)$

$k_{F}=$ mass transfer coefficient for the feed phase $\left(\mathrm{cm} \mathrm{min}^{-1}\right)$

$k_{M}=$ mass transfer coefficient for the organic phase entrapped in the membrane pores $\left(\mathrm{cm} \mathrm{min}^{-1}\right)$

$L=e$ ffective length of a hollow fiber (cm)

$L T U=$ length of transfer unit $(\mathrm{cm})$

$m_{A}=$ partition coefficient of a pesticide between organic and acceptor phase

$m_{F}=$ partition coefficient of a pesticide between organic and feed phase

$N=$ number of hollow fibers in contactor

$n_{A}=$ number of moles of pesticide in the acceptor phase (mol)

$n_{F}^{i n}=$ initial number of moles of pesticide in feed phase (mol)

$N T U=$ number of transfer units

$Q_{F}=$ feed flow rate $\left(\mathrm{cm}^{3} \mathrm{~min}^{-1}\right)$

$R=$ overall mass transfer resistance $\left(\mathrm{cm}^{-1} \mathrm{~min}\right)$

$r_{F}=$ mass transfer resistance in the feed stream $\left(\mathrm{cm}^{-1} \mathrm{~min}\right)$ 
$r_{M}=$ mass transfer resistance in the organic phase entrapped in the membrane pores $\left(\mathrm{cm}^{-1} \mathrm{~min}\right)$

$t=$ extraction time (min)

$t_{R}=$ the residence time of the feed stream (min)

$V_{A}=$ volume of the acceptor phase $\left(\mathrm{cm}^{3}\right)$

$V_{F}=$ volume of the feed phase $\left(\mathrm{cm}^{3}\right)$

Greek Symbols

$\delta=$ membrane thickness $(\mathrm{cm})$

$\varepsilon=$ membrane porosity

$\tau=$ tortuosity of membrane pores

\section{REFERENCES}

(1) Council Directive (2006/11/EC) on pollution caused by certain dangerous substances discharged into the aquatic environment; Offic. J. Euro. Union. 2006, L64, 52.

(2) Law on Integrated environmental pollution prevention and control; Official Gazette of the Republic of Serbia (in Serbian) 2004, 135.

(3) http://www.vilanova.cat/content/tramits/RE-AJU-49.pdf

(4) Sonune, A.; Ghate, R. Developments in wastewater treatment methods. Desalination 2004, 167, 55.

(5) Nanoti, A.; Ganguly, S. K.; Goswami, A. N.; Rawat, B. S. Removal of phenols from wastewater using liquid membranes in a microporous hollow-fiber-membrane extractor. Ind. Eng. Chem. Res. 1997, 36, 4369. 
(6) Ren, Z.; Zhang, W.; Liu, Y.; Dai, Y.; Cui, C. New liquid membrane technology for simultaneous extraction and stripping of copper (II) from wastewater. Chem. Eng. Sci. 2007, 62, 6090.

(7) Tandlich, R. Liquid membranes, principles and applications in chemical separations and wastewater treatment; Elsevier: Amsterdam, 2010.

(8) Kocherginsky, N. M.; Yang, Q.; Seelam, L. Recent advances in supported liquid membrane technology. Sep. Sci. Technol. 2007, 53, 171.

(9). San Román, M. F.; Bringas, E.; Ibañez, R.; Ortiz, I. Liquid membrane technology: fundamentals and review of its applications. J. Chem. Technol. Biotechnol. 2010, 85, 2.

(10) Yang, Q.; Kocherginsky, N. M. Copper removal from ammoniacal wastewater through a hollow fiber supported liquid membrane system: Modeling and experimental verification. $J$. Membr. Sci. 2007, 297, 121.modzul

(11) Güell, R.; Anticó, E.; Salvadó, V.; Fontàs, C. Efficient hollow fiber supported liquid membrane system for the removal and preconcentration of $\operatorname{Cr}(\mathrm{VI})$ at trace levels. Sep. Purif. Technol. 2008, 62, 389.

(12) Liu, Y.; Shi, B. Hollow fiber supported liquid membrane for extraction of ethylbenzene and nitrobenzene from aqueous solution: A Hansen Solubility Parameter approach. Sep. Purif. Technol. 2009, 65, 233.

(13) Kumrić, K.; Trtić-Petrović, T.; Koumarianou, E.; Archimandritis, S.; Čomor, J. Supported liquid membrane extraction of ${ }^{177} \mathrm{Lu}(\mathrm{III})$ with DEHPA and its application for purification of ${ }^{177}$ Lu-DOTA-lanreotide. Sep. Pur. Techn. 2006, 51, 310. 
(14) Ansari, S. A.; Mohapatra, P. K.; Prabhu, D. R.; Manchanda, V. K. Evaluation of $N, N, N^{\prime}, N^{\prime}$-tetraoctyl-3-oxapentane-diamide (TODGA) as a mobile carrier in remediation of nuclear waste using supported liquid membrane. J. Membr. Sci. 2007, 298,169.

(15) Trtić-Petrović, T.; Đorđević J.; Dujaković, N.; Kumrić, K.; Vasiljević T.; Laušević M. Determination of selected pesticides in environmental water by employing liquid-phase microextraction and liquid chromatography-tandem mass spectrometry. Anal. Bioanal. Chem. 2010, 397, 2233.

(16) Pabby, A. K.; Sastre, A. M. State-of-the-art review on hollow fibre contactor technology and membrane-based extraction processes. J. Membr. Sci. 2013, 430, 263.

(17) Köck-Schulmeyer, M.; Villagrasa, M.; López de Alda, M.; Céspedes-Sánchez, R.; Ventura, F.; Barceló, D. Occurrence and behavior of pesticides in wastewater treatment plants and their environmental impact. Sci. Total Environ. 2013, 458-460, 466.

(18) Morasch, B.; Bonvin, F.; Reiser, H.; Grandjean, D.; de Alencastro, L. F.; Perazzolo, C.; Chèvre, N.; Kohn, T. Occurrence and fate of miropollutants in the Vidy Bay of Lake Geneva, Switzerland. Part II:Micropollutant removal between wastewater and raw drinking water. Environ. Toxicol. Chem. 2010, 29, 1658.

(19) Singer, H.; Jaus, S.; Hanke, I.; Lück; J. Hollender, A.; Alder, A. C. Determination of biocides and pesticides by on-line solid phase extraction coupled with mass spectrometry and their behaviour in wastewater and surface water. Environ. Pollut. 2010, 158, 3054.

(20) Gupta, V. K.; Gupta, B.; Rastogi, A.; Agarwal, S.; Nayak, A. Pesticides removal from waste water by activated carbon prepared from waste rubber tire. Water. Res. 2011, 45, 4047. 
(21) Trtić, T. M.; Vladisavljević, G. T.; Čomor, J. J. Dispersion-Free Solvent Extraction of Thallium(III) in Hollow Fiber Contactors. Sep. Sci. Technol. 2000, 35, 1587.

(22) Trtić, T. M.; Vladisavljević, G. T.; Čomor, J. J. Single-stage and two-stage solvent extraction of $\mathrm{Tl}(\mathrm{III})$ in hollow-fiber contactors under recirculation mode of operation. Sep. Sci. Technol. 2001, 36, 295.

(23) Alonso, A. I.; Pantelides, C. C. Modelling and simulation of integrated membrane processes for recovery of Cr(VI) with Aliquat 336. J. Membr. Sci. 1996, 110, 151.

(24) Prasad, R.; Sirkar, K. K. Membrane-based solvent extraction in Membrane handbook; Van Nostrand Reinhold: New York, 1992.

(25) Schlosser,Š.; Sabolová, E.; Kertész, R.; Kubišová, L. Factors influencing transport through liquid membranes and membrane based solvent extraction. J. Sep. Sci. 2001, 24, 509.

(26) Hansson, H.; Colmsjö, A.; Nilsson, U. Study of mass transfer in a dynamic hollow-fibre liquid phase microextraction system. J. Sep. Sci. 2010, 33,112.

(27) Harriott, P.; Ho, S. V. Mass transfer analysis of extraction with a supported polymeric liquid membrane. J. Membr. Sci. 1997, 135, 55.

(28) Trébouet, D.; Burgard, M.; Loureiro, J. M. Guidelines for the application of a stationary model in the prediction of the overall mass transfer coefficient in a hollow fiber membrane contactor. Sep. Purif. Technol. 2006, 50, 97.

(29) Reid, R. C.; Prausnitz, J. M. The Properties of Gases and Liquids; McGraw-Hill: New York, 1977. 
(30) Tomlin, C. D. S.; The pesticide manual (15th edition); British Crop Protection Council; Hampshire: UK, 2009.

(31) Zorita, S.; Mårtensson, L.; Mathiasson, L. Hollow-fibre supported liquid membrane extraction for determination of fluoxetine and norfluoxetine concentration at ultra trace level in sewage samples. J. Sep. Sci. 2007, 30, 2513.

(32) Trtić-Petrović, T. M.; Jönsson, J. Å. Application of SLM extraction for investigation of metal-humic acid bindings. Desalination 2002, 148, 247.

(33) Guha, A. K.; Yun, C. H.; Basu, R.; Sirkar, K. K. Heavy metal removal and recovery by contained liquid membrane permeator. AIChE J. 1994, 40, 1223.

(34) Prasad, R.; Sirkar, K. K. Dispersion-free solvent extraction with microporous hollow-fiber modules. AIChE J. 1988, 34, 177.

(35) Gabelman, A.; Hwang, S. T. Hollow fiber membrane contactors. J. Membr Sci. 1999, 159, 61.

(36) Keurentjes, J. T. F.; Nabuurs, L. J. W. M.; Vegter, E. A. Liquid membrane technology for the separation of racemic mixtures. J. Membr. Sci. 1996, 113, 351.

(37) Prasad, R.; Sirkar, K. K. Hollow fiber solvent extraction: Performances and design. J. Membr. Sci. 1990, 50, 153. 